\title{
ENHANCING LIBRARY RESOURCES ACCESS FOR DIFFERENT ABLED PERSON THROUGH ICT
}

\author{
Suresh b. Solanki ${ }^{1}$ and shishir mandaliya ${ }^{2}$ \\ ${ }^{1}$ Asst.librarian, cmpica, charusat, \\ ${ }^{2}$ I/c librarian bhaikaka library, s.p.uni.v.v.nagar
}

\begin{abstract}
This study focuses on the existing scenarios of the library services for the differently-abled students being provided by some university libraries in india. it provides results of the study. till now academic library services for these persons are inadequate. recently some university libraries have taken steps in this regard. unesco and ifla have issued guidelines to provide equal library services to all including people with disabilities. the governments of india and university grants commission have also issued guidelines in this regard. this study highlights the special equipments, infrastructure and services that the libraries are expected to provide for the disabled pupil.
\end{abstract}

\section{KEYWORDS}

Differently abled person, library, access of library resources, ict

\section{INTRODUCTION}

Barrier free environment in an academic institution helps in enhancing the performance and also helps in making a person independent. Differently abled person's requirements for a barrier free environment in terms of infrastructure will be exclusive in terms of making them comfortable, safe and independent. service provided by libraries for different abled person who were defined as those with greater degree of visual impairment than would be associated with the description "partially sighted" the main purpose of the study is to contribute to reassessment of the role of all libraries in the provision of services to different abled person.

\section{DEFINITION OF TERMINOLOGIES:}

\subsection{Different abled people:}

Differently abled is a euphemistic term for someone who might formerly have been classed as disabled, handicapped, challenged, or having special needs. it can apply to people with predominantly physical or mental challenges. the description is thought to be more politically correct in some circles because it recognizes that even if people have mental and/or physical impairments, they still have abilities, contrary to the picture painted with the terms disabled or handicapped.

\subsection{Academic libraries}

An academic library is a library that is attached to a higher education institution which serves two complementary purposes to support the school's curriculum, and to support the research of the university faculty and students. it is unknown how many academic libraries there are internationally. 
A library is a collection of sources of information and similar resources, made accessible to a defined community for reference or borrowing. a provided physical and digital access to material, and may be a physical building or room or a virtual space or both.

\subsection{ICT}

Information and communications technology (ict) is often used as an extended synonym for information technology (it), it is a more extensive term (i.e. more broad in scope) that stresses the role of unified communications[1] and the integration of telecommunications (telephone lines and wireless signals), computers as well as necessary enterprise software, middleware, storage, and audio-visual systems, which enable users to access, store, transmit, and manipulate information

\section{TYPES OF DISABILITY}

Physical disability: a physical disability is a limitation on a person's physical functioning, mobility, dexterity or stamina. other physical disabilities include impairments which limit other facets of daily living, such as respiratory disorders, blindness, epilepsy and sleep disorders.

Sensory disabilities: sensory impairment is when one of your senses; sight, hearing, smell, touch, taste and spatial awareness, is no longer normal. examples - if you wear glasses you have sight impairment, if you find it hard to hear or have a hearing aid then you have a hearing impairment.

3.2.1 vision impairment

3.2.2 hearing impairment

3.2.3 olfactory and gustatory impairment

3.2.4 somatosensory impairment3.2.5 balance disorder 3.3

intellectual disabilities

3.4 mental health and emotional disabilities

3.5 pervasive developmental disorders

3.6 developmental disability

3.7 nonvisible disabilities

\section{Disabled population and type of disability:}

Census 2001 has revealed that over 21 million people in India as suffering from one or the other kind of disability. this is equivalent to $2.1 \%$ of the population. among the total disabled in the country, 12.6 million are males and 9.3 million are females. although the number of disabled is more in rural and urban areas. such proportion of the disabled by sex in rural and urban areas. such proportion has been reported between 57-58 percent for males and 42-43 percent females. the disability rate (number of disabled per 100,000 populations) for the country as whole works out to 2130. this is 2,369in the case of males and 1,874 in the case of females.

Among the five types of disabilities on which data has been collected, disability in seeing at $48.5 \%$ emerges as the top category. others in sequence are: in movement $(27.9 \%)$, mental $(10.3 \%)$, in speech $(7.5 \%)$, and in hearing $(5.8 \%)$. the disabled by sex follow a similar pattern except for that the proportion of disabled females is higher in the category in seeing and in hearing.

Across the country, the highest number of disabled has been reported from the state of uttar pradesh (3.6 million). significant numbers of disabled have also been reported from the state like bihar (1.9 million), west bengal (1.8million), tamil nadu and 
Maharashtra (1.6 million each). tamil nadu is the only state, which has a higher number of disabled females than males. among the states, arunachal pradesh has the highest proportion of disabled males $(66.6 \%)$ and lowest proportion of female disabled

\begin{tabular}{|l|l|l|}
\hline & Population & Percentage (\%) \\
\hline total population & $1,028,610,328$ & 100.0 \\
\hline total disabled population & $21,906,769$ & 2.1 \\
\hline disability rate ( per lakh population) & 2,130 & - \\
\hline Type of disability & & \\
\hline (a) in seeing & $10,634,881$ & 1.0 \\
\hline (b) in speech & $1,640,868$ & 0.2 \\
\hline (c) in hearing & $1,261,722$ & 0.1 \\
\hline (d) in movement & $6,105,477$ & 0.6 \\
\hline (e) mental & & 0.2 \\
\hline
\end{tabular}

Table: number of disabled population and type of disability

\section{ADDRESSING LIBRARY SERVICES FOR PERSONS WITH DISABILITIES}

All library materials should ideally be accessible for all persons with disabilities. there are various ways to achieve this goal. libraries should acquire talking (books, newspapers, periodicals), video/dvd books with subtitles and/or sign language, braille books, large print books, accessible e-books, easy-to-read books, tactile picture books or other non-print materials. improve and facilitate access to alternative-format library materials for persons with disabilities collections of alternative-format library materials for readers with disabilities exploring ways to create and improve library services and resources for people with print disabilities. facilitate information exchange, resource-sharing among libraries serving persons with disabilities and meet their changing needs. providing information and expertise to the general community and organizations about the provision of library services to persons with disabilities.

\subsection{Library services for people with print disabilities}

The library needs of people with print disabilities are generally the same as those of sighted people. However, by definition, people with print disabilities cannot use 
International Journal of Information Sciences and Techniques (IJIST) Vol.6, No.1/2, March 2016

conventional print materials. they must depend upon large type, audio (spoken word), tactile devices (such as braille) and/or mechanical or optical aids - or a combination of these.

Collections for people with print disabilities should include:

Talking books, audio magazines and newspapers;

Audio tape, cd/dvd, or in daisy format;

Large-print books;

Computer files of text;

Braille and other tactile materials;

Audio-descriptive videos.

\subsection{Library services for people with deaf or hearing impaired}

Basic collection of materials in formats that are readily accessible to deaf and hearing impaired, so we need to development services to assist them, the primary goal of any specialized program to the deaf and hearing impaired must be to provide equal access to all programs and services that are enjoyed by the library's hearing clientele.

Books and pamphlets on sign language, dictionaries of signs; highInterest/low-vocabulary reading materials;

DVDs contain sub-titles as a standard feature and illustrated materials;

Films and videos including closing caption video;

Loop system, audio loop and counter loop;

Telecommunication devices

\subsection{Library services for cognitive disabilities}

People who are cognitively delayed may need types of support. planning for libraries can often include individuals with cognitive disabilities because many function at a fairly high level. they have preferences and can articulate them, and they can give insight into the problems they have in using a library. every library should provide a basic collection covering a broad range of information as an integral part of the library collection. people with cognitive and intellectual disabilities will benefit from access to:

Books in enlarged print;

High-interest, low-vocabulary materials and books;

Books on tape-and-text kits;

Illustrated materials (picture books), audio materials and music collections;

Spoken-word collections;

Audio and video tape in daisy format.

\subsection{Library services for persons with physical disabilities}

Persons with physical disabilities may need assistance in doing some of the physical tasks that are involved in using the library.they need access computers for reading at the library with the following software:

Voice recognition;

Word prediction;

Screen enlargement; 
International Journal of Information Sciences and Techniques (IJIST) Vol.6, No.1/2, March 2016

Software for converting print documents;

Scan and read programs;

Text highlighting and advanced reading in different formats.

\subsection{Electronic books}

E-books are an extremely popular topic these days. e-books are an especially exciting development for readers with disabilities because their properties make them ideal for finding alternative forms of access. when an e-book is presented in an accessible format on an accessible e-book reader, the user can choose to read the book using text-to-speech, braille, or magnification. Furthermore, accessible e-books in an open market benefit everyone. For persons with disabilities their need can be fulfilled very simply, with large print or an existing pdf version whereas others find a fully navigable structured file such as a daisy file, an epub 3 file or an html based e-book that they can use with text to speech software essential. Other readers with blind prefer braille by using a standard embossed braille edition or by accessing an electronic publication through a refreshable braille device.

\subsection{Digital accessible information systems (daisy) format}

This has become the foremost specialist standard format for use in the creation of accessible versions for the print impaired. it can be the most accessible file format available. it is essentially an $\mathrm{xml}$ based e-book format created by the daisy consortium, an organization which represents libraries for people with print disabilities. a daisy book can be explained as a package of digital files that may include: one or more digital audio files containing a human or pre-recorded synthesized narration of part or all of the source text; a marked-up file containing some or all of the text; a synchronization file to relate markings in the text file with time points in the audio file; and a navigation control file which enables the user to move smoothly between files while synchronization between text and audio is maintained.

\section{International day of the differently abled persons:}

'International day of the differently abled' is observed on $3^{\text {rd }}$ December every year by the state government in accordance with the declaration of the united nations organization. the main aim of observing this day is to encourage the differently abled persons to showcase their skills and abilities in various fields of arts and sports. In connection with the international day of the differently abled, "state level sports meet" is conducted. As many as 5000 differently abled children from all over the state participate in the events. Several sports and games are conducted and prizes are distributed to winners and certificates issued to all the participants. On this day, cultural programmes are also conducted and state awards are distributed to the best employer, best social worker, best employee, best teacher and best institution, who render outstanding service for the welfare of the differently abled persons. Aids and appliances are also distributed on this occasion. the government has issued orders granting special casual leave for this day to all the differently abled persons employed in government departments/ undertakings to enable them to participate in the function. 
International Journal of Information Sciences and Techniques (IJIST) Vol.6, No.1/2, March 2016

\section{INFORMATION COMMUNICATION TECHNOLOGY IN EDUCATION:}

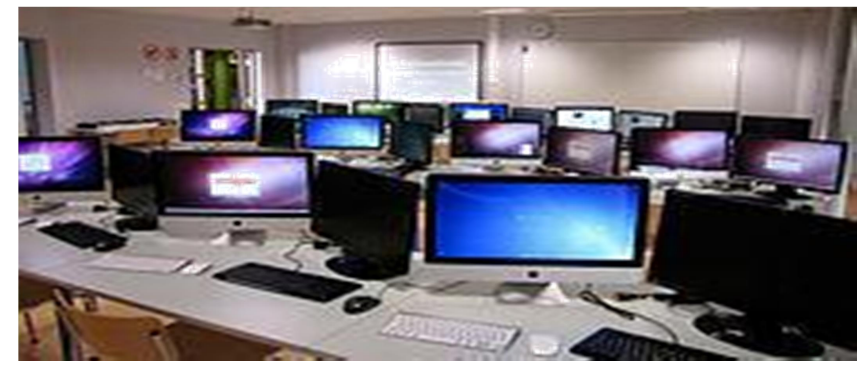

Figure no-1 ICT in education

Information and communication technology can contribute to universal access to education, equity in education, the delivery of quality learning and teaching, teachers' professional development and more efficient education management, governance and administration. UNESCO takes a holistic and comprehensive approach to promoting ICT in education. access, inclusion and quality are among the main challenges they can address. The organization's intersectral platform for ict in education focuses on these issues through the joint work of three of its sectors: communication \& information, education and science.

\section{ICT FOR THE DIFFERENTLY-ABLED:}

Some of the most relevant and innovative applications of information and communication technology for development (ict4d) can be found in interventions developed for the differently abled. In India alone, close to 20 million people suffer from some sort of physical disability. of these, over 10 million people, i.e. just under $1 \%$ of our population (or $50 \%$ of all physically disabled), suffer from disability in sight. this is followed by $0.6 \%$ of the population facing locomotive disabilities, $0.2 \%$ of the population is speech impaired and $0.1 \%$ is hearing impaired. the development of ict4d presents new opportunities for these individuals to mainstream their activities and lifestyles, promoting their inclusive growth.

Despite having no cognitive damage, most students with physical disabilities are seen lagging behind those without. these disadvantages unfairly suppress their morale, and they seem to withdraw from regular schooling. this is chiefly because they are unavailable to find the infrastructure and environment to support their learning needs. ict4d has the potential to greatly support students with disabilities, and provide them with the opportunities to learn to the fullest, alongside their peers. when we discuss ict interventions for disabled students, there are several types of interventions that come to mind. there are tools that enable easier access to technology such as computers or cell phones, making using these devices simpler; newer technology or devices designed to cater to their specific needs; and applications accessed through smart devices such as cell phones and tablets.

Presented below are some innovations that have really helped those with physical disabilities. they have really helped to bridge the gap between learning and access of these individuals and that of those without disabilities. 
International Journal of Information Sciences and Techniques (IJIST) Vol.6, No.1/2, March 2016

\subsection{Devices and software:}

\subsubsection{Jaws}

Jaws (Job access with speech) is one of the most popular and effective softwares developed for the blind or visually impaired. The software enables visually challenged readers to read a computer screen with the help of a text-to-speech output or a refreshable braille display. Such easy computer access for the blind would be unimaginable without jaws.

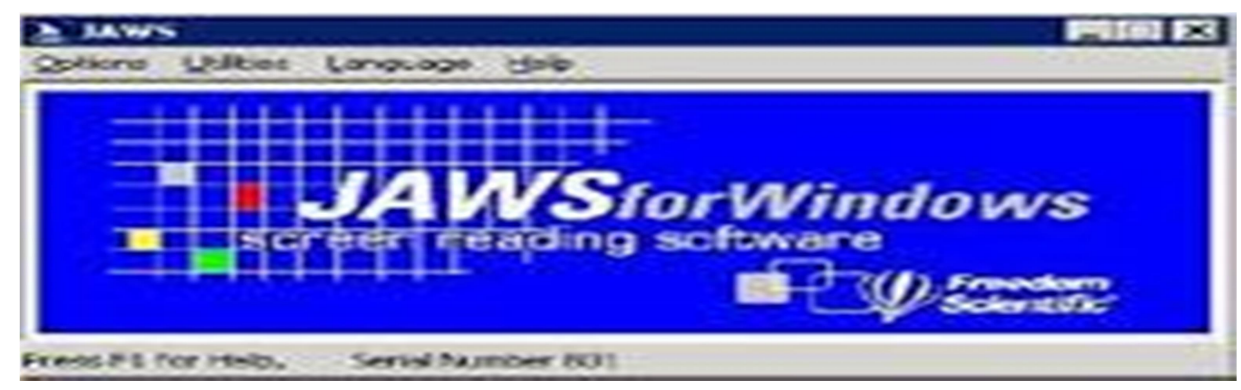

Figure no-2(job access with speech)

Similar to jaws is the 'shruti' system which is currently deployed in 40 schools across India by the government of India. It works in almost the same way as jaws, but is much cheaper to access. computer usage, hitherto impossible for the blind, can now be accessed for a wide range of learning purposes.

\subsubsection{Sparsha}

Sparsha is a toolset for the blind. sparsha can translate the text on screen to bharati braille - a unified braille script used to write english languages using cells containing six braille dots. apart from english, the languages supported by sparsha include hindi, bengali, assamese, marathi, gujarati, oriya, telugu and kannada. not only can it represent the text on screen in braille, but it can also transliterate english into any of the above mentioned scripts. It has the facility to save the document, as well, so that it can be later printed using a braille printer. Sparsha goes a step beyond being just a screen reader and also allows for reverse transliteration, so that braille can be converted to text on screen. This has greatly reduced the communication gap between the visually impaired and other sighted people, making it far more seamless.

\subsubsection{Sanyog}

Since its inception in 2001, sanyog - a project of the Indian institute of technology, kharagpur has impacted the lives of several speech impaired children, and enabled them to express themselves in creative ways. It is an alternative and augmented communication tool that enables students with high motor disability use special access switches to represent their thoughts through icons and images. It then takes these images to form syntactically and semantically correct sentences in english, as well as in indian languages such as bengali and hindi. further, it also enables users to personalize icons to further represent their thoughts more accurately. The sentence thus formed can then be spoken out using the text to speech system made specifically for sanyog. 


\subsection{Applications}

\subsubsection{Applications for the blind}

Some interesting applications for the visually impaired are available in the market such as ariadne GPS. This app uses GPS to track the position of the blind, and helps them navigate using talking maps. It vibrates the device when crossing a street, and can also announce bus and train stops. This application can be used on any device enabled with google maps, and has made commuting

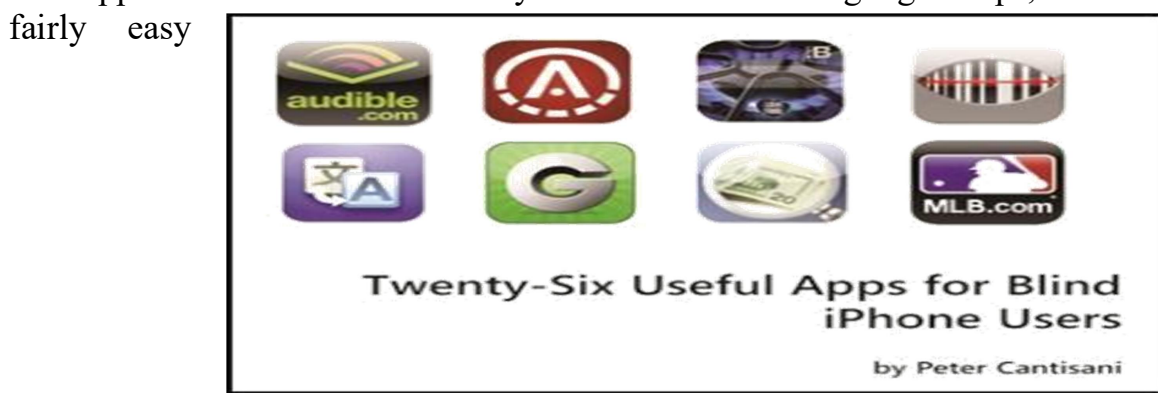

for the blind.

Figure no-3 applications for the blind

Other apps for the blind that can be used to procure information are colour id and vizwiz. Color id helps the visually impaired recognize the colours of the things around them. All they have to do is click a picture of the object and the app recognizes its colour and says it aloud. Similarly, any product information can be gathered from vizwiz by clicking and submitting its pictures. The picture can be sent to a web worker, an online repository or to a contact through email or twitter. A question must be asked with the image by recording the question, and a verbal response is received.

\subsubsection{Applications for the hearing impaired}

$\mathrm{z} 4$ mobile is a valuable app to help the hearing impaired communicate. It enables them to make point-to-point calls by creating a video session with an interpreter. The interpreter interprets the sign language of the hearing impaired caller and translates it into speech for the hearing member.

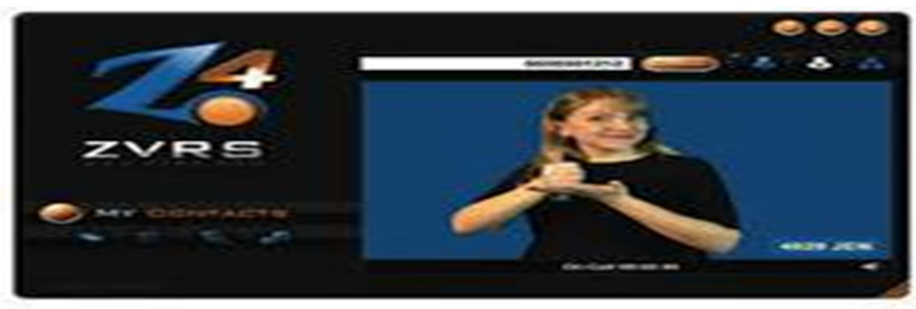

Figure no-4 applications for the hearing impaired

Many times, the hearing impaired is in danger as they are not able to hear the alarms and alerts set off by danger. To address this, tap tap is an app that will vibrate and flash light from the 
International Journal of Information Sciences and Techniques (IJIST) Vol.6, No.1/2, March 2016 device if there is any noise in the vicinity. For example, if there is knocking, if someone is shouting or if smoke alarm goes off, tap tap will send an alert to its user so that the person with hearing impairment can be alerted.

\subsubsection{Applications for the speech impaired}

Communication is very frustrating for someone with speech impairments, simple because it is so hard for them to express themselves. The development of applications for such students has really benefitted them by reducing the stress of daily communication. For example, proloquo2go is an application that uses pictures in place of words. Students choose pictures that symbolize different nouns, verbs or phrases and the application would form a sentence and read it aloud. This is a lot more effective for students with speech disorders than text to speech type applications, and has really helped them.

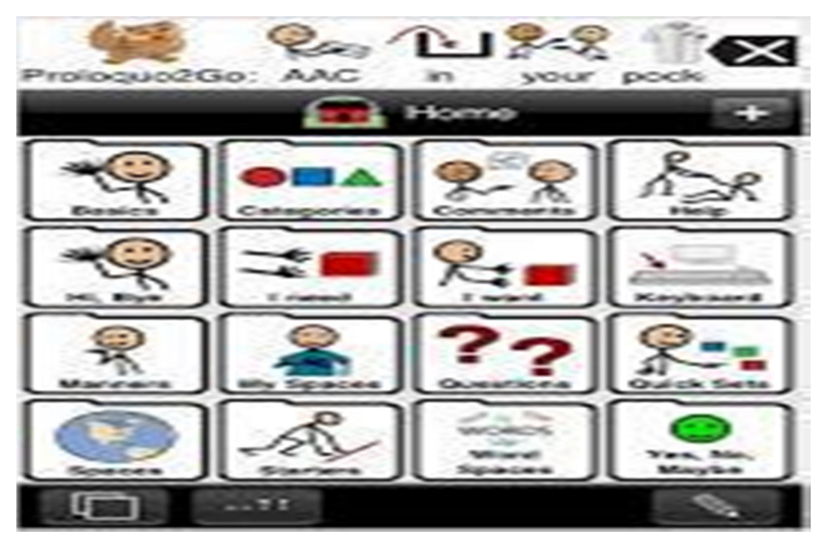

Figure no-5 Applications for the speech impaired

Taptotalk is another application that uses the same principle of image-to-voice to help children with speech disabilities talk. A feature of taptotalk is also its ability to store photographs and pictures from other sources, making the images used for communication more relevant and specific.

Games such as speech with milo, speech hangman, and tiga talk speech therapy games allow students with speech impairments to articulate and practice speaking and sequencing sentences in a fun way.

Such developments in ict4d have opened up a new world for those with disabilities. they have helped student's better cope with their day-to-day requirements, empowering them to live more independently. They facilitate communication, paving way for more inclusive classrooms, and better access to technology for accessing online resources, making documents, etc. Further development and research in this area will truly benefit and impact the lives of the differently able students.

\subsection{ICT today:}

In modern society ICT is ever-present, with over three billion people having access to the internet. With approximately 8 out of 10 internet users owning a smartphone, information and data are increasing by leaps and bounds. This rapid growth, especially in developing countries, has led ict to become a keystone of everyday life, in which life without some facet of technology 
International Journal of Information Sciences and Techniques (IJIST) Vol.6, No.1/2, March 2016 renders most of clerical, work and routine tasks dysfunctional. The most recent authoritative data, released in 2014, shows "that internet use continues to grow steadily, at $6.6 \%$ globally in 2014 (3.3\% in developed countries, $8.7 \%$ in the developing world); the number of internet users in developing countries has doubled in five years (2009-2014), with two thirds of all people online now living in the developing world however, hurdles are still at large. "Of the 4.3 billion people not yet using the internet, 90\% live in developing countries. In the world's 42 least connected countries (lccs), which are home to 2.5 billion people, access to icts remains largely out of reach, particularly for these countries' large rural populations ict has yet to penetrate the remote areas of some countries, with many developing countries dearth of any type of internet. This also includes the availability of telephone lines, particularly the availability of cellular coverage, and other forms of electronic transmission of data. The latest "measuring the information society report" cautiously stated that the increase in the aforementioned cellular data coverage is ostensible, as "many users have multiple subscriptions, with global growth figures sometimes translating into little real improvement in the level of connectivity of those at the very bottom of the pyramid; an estimated 450 million people worldwide live in places which are still out of reach of mobile cellular service favorably, the gap between the access to the internet and mobile coverage has decreased substantially in the last fifteen years, in which "2015 is the deadline for achievements of the un millennium development goals (mdgs), which global leaders agreed upon in the year 2000, and the new data show ict progress and highlight remaining gaps deadline for achievements of the un millennium development goals (mdgs), which global leaders agreed upon in the year 2000, and the new data show ict progress and highlight remaining gaps ICT continues to take on new form, with nanotechnology set to usher in a new wave of ict electronics and gadgets. ICT newest editions into the modern electronic world include smart watches, such as the apple watch, smart wristbands such as the nike+ fuelband, and smart tvs such as google tv. With desktops soon becoming part of a bygone era, and laptops becoming the preferred method of computing, ict continues to insinuate and alter itself in the ever-changing globe.

\section{CONCLUSION:}

Libraries play a vital role in the lives of persons with disabilities by facilitating their full participation in society. Libraries should use strategies based upon the principles of universal design to ensure that library policy, resources and services meet the needs of all people. We need to plan technological solutions and access points for example (telecentre), based on the concepts of universal design, are essential for effective use of information and other library services by all people. Libraries should work with persons with disabilities, local communities, organizations and vendors to integrate assistive technology into their facilities and services to meet the needs of people with a broad range of disabilities, including learning, mobility, sensory and developmental disabilities. Library staff should be aware of how available technologies address disabilities and know how to assist all users with library technology.

\section{REFERENCES}

[1] nabil eid, innovation and technology for person with disabilies,

[2] http://www.telecenter.org/profile / nabileid

[3] wiki educator, how ict play vital role for differently abled students

[4] vincent o. ekwelem, library services to disabled students in the digital era, university of nigeria.

[5] www.india gov.in

[6] m.m.koganuramath, learning research center for the visually impoird students in the university to faster inclusive education, tata institute of social science, mumbai.

[7] craddock, p. 1985. the university library and blind people: a survey and review of current practice, british lib. 
International Journal of Information Sciences and Techniques (IJIST) Vol.6, No.1/2, March 2016

[8] craddock, p. 1986.university libraries and differently abled people: what kind of relationship? p.1420 .

[9] tripathi p.2012.infrastucture facilities for differently abled students-a comparative study of government and non-government institutions, international res.journal of social science.vol.1 (3), p.21-25.

[10] marry cassner.2011.diffrently able: a review of academic library websites for people with disabilities, uni.of nebraska-london,-p.33-51.

[11] protap, c.2009.designing barrier free services for visually challenged persons in the academic libraries in india, ical, p.626-629.

[12] marsh, joanna.2014.academic library services for differently-abled petrons, emporia state university, and p.1-15.

[13] http://censusindia.gov.in/census_and_you/disabled_population.aspx

[14] http://www.languageinindia.com/jan2014/disabilityinindia2011data.pdf

[15] http://mospi.nic.in/mospi_new/upload/revised_disability_manual_20june12.pdf

[16] http://timesofindia.indiatimes.com/india/disabled-population-up-by-22-4-in-200111/articleshow/28072371.cmshttp://mospi.nic.in/mospi_new/upload/revised_disabili ty_manual_20june12.pdf

\section{Author Short Biography}

SureshKumar B. Solanki

Asst.Librarian, CMPICA, Charusat, Changa (M.A., MLISc, M.Phil. (Lib.Sc.)

Ph.D Lib.Sc. (Pursuing)

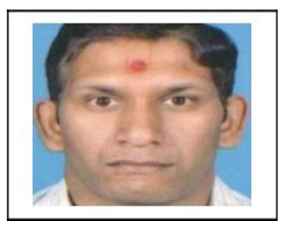

